\title{
Creating a Partnership Conducive Environment: A Collaborative Approach To Service Delivery
}

\author{
Lucila Spigelblatt
}

\begin{abstract}
This article explores, from a practitioner's point of view, some of the challenges and learning opportunities that occur when organizations partner-up to meet the needs of refugees. This article also highlights the factors that have contributed to the success of a seven-year "service partnership." The author proposes that the process to establish the partnership is as important as the actual service delivery. The commitment and investment of time and resources are essential requirements for the sustainability of a collaborational approach to providing services for refugees.
\end{abstract}

\section{Résumé}

Cet article explore, $d u$ point de vue $d u$ praticien, quelques-uns des défis et des possibilitcs d'apprentissage qui se présentent lorsque des organisations s'associent pour répondre aux besoins des réfugiés. L'article met aussi en relief les facteurs qui ont contribué au succès d'un "partenariat de services » qui a duréseptans. L'auteure propose la thèse que le processus pourl'établissement du partenariat est aussi important que la prestation mêmedu service. Un engagementet un investissement en tempseten ressources sont des conditions essentielles pour qu'une approche participative en matière de services aux réfugiés devienne durable.

\section{Introduction}

There are few organizations able to meet by themselves the entire complex needs of refugees. Since there are numerous organizations that provide excellent services to meet some of these needs,

Lucila Spigelblatt is the Deputy Executive Director of the Catholic Immigration Centre (CIC) in Ottawa and a member of the Board of Directors of the Ontario Council of Agencies Serving Immigrants (OCASI). collaboration among service providers would seem an obviousstrategy. Why is it then, that "service-partnerships" are not more predominant as a model for service delivery? Perhaps the developmental stages of a service partnership should be considered as two different projects with overlapping goals. One of the projects would focus on the services delivered to refugees and immigrants. The other project, equally important, would concentrate in creating a sustainable arrangement for collaboration between the service providers.

Using the Multicultural Liaison Officer (MLO) Programme in Ottawa as an example of a "service partnership", this article will focus on some of the agreements and understandings necessary to create an environment conducive to collaboration between service providers. These agreements and understandings promote partnership among organizations serving refugees and immigrants through organizational cultural mediation.

\section{Critical Assumptions}

To explore the operational framework, theMLOprogrammein Ottawahasbeen analyzed as a case study in service organizations partnership. As a programmemanager for settlementservices designed to assist refugees and immigrants to Canada, my work experience during the past twelve years has focused in two different areas: one in the design and implementation of programmes to assist in the resettlement and integration of refugees and immigrants into Canadian society; the other in the exploration of "cultural competency," defined as the set of skills that facilitate respectful and productive interaction between people who mightnot share the same cultural context.

Perhaps because of this dual role, I have noticed on several occasions that there seems to exist an underlying assumption on the part of funders and service providers that because there is a shared goal (meeting the needs of refugees), the rest of the service delivery puzzle should fall in place with little difficulty. This assumption may not hold true in practice.

Over the past decade there has been a push by funders to encourage immigrant settlement agencies to develop partnerships with mainstream agencies in order to address the issue of access to services. There has also been a tendency for funders to see themselves as partners in the delivery of service. While the shift to collaborative delivery systems is desirable, this has also been a stressful time for settlement services that participate in collaborative programmes either by a sense of obligation from the funder or by independent agency direction in programming. (Pinto 1998, pp. 6-7)

Some of the obstacles to collaborative delivery systems originate in different areas. A critical barrier in the contemporary market oriented policies is a scarcity of resources for delivery of social services. Second, constraint resources lead to competition, not collaboration. Third, the common goal, that is serving the needs of refugees and immigrants in this practical case study.

We hope we have been thoughtful and strategic in choosing our bedfellows, mindful of staying true to our mandate, principles and standards while striking a balance among the various roles we play in these partnerships. Maintaining the 'core' of who you are and the relationship you share with your community amid these demands may become a greater challenge yet. If we are to accept the challenges and risks of experimenting with new and different approaches, we must also be key players in defining and guiding the direction of the trend. (Di Zio 1998, p. 3) 
Then, the challenges we face may force us to ask: How do we, the two organizations involved, capture a common goal and sustain it amidst a constantly changing environment?

Frequently, the organizations and their funders sit down, hammer-out extensive agreements as to the kinds of services and the budgets allocated to the new "partnership," agree to the lines of responsibility and communication, and hire the best qualified staff. From that point on, they tend to assume that the programme is ready to proceed with service delivery and most of the issues that may arise will be client-related.

While I doubt that anyone would challenge the complexity of the needs of refugees or the willingness and capacity of most organizations dedicated to facilitating their resettlement, I believe that the difficulties added to the service delivery equation when we attempt to collaborate, are underestimated. Perhaps, the key assumption threatening the success of a service delivery partnership is that the initial investment of staff time and resources required to establish a working relationship among the service providers may be assumed to be of marginal importance. This may be so because it is not spent on service delivery to clients.

I call this initial investment "Service Interpretation," for lack of better terminology, and I hope it conveys a concept that is similar to cultural interpretation in that it "interprets" the culture of one organization to the other. I hesitate in my choice of words because, in many cases, the most difficult negotiations between potential partners centre on the different meanings assigned to key words describing services or qualities. Typical examples of this would be the discussions around what "counselling "means (settlement workers "counsell" their clients, so do psychologists, social workers, guidance counsellors, etc., but each one means something different).

Tensions also arise over traditional concepts versus more recent interpretations or practices. Does "professional" mean that you require some sort of regulatory body to certify a level of competency? Who determines what is "professional?"
Most of the decisions a group makes are routine. The issues are familiar, the solutions are obvious and the implementation can be accomplished with a bare minimum of planning and organizing. Not all problems are routine though and what most people don't realize is that this model does not work when the problem is a difficult one. When a group attempts to solve a difficult problem as though it were a routine problem, they will very likely make a decision that simply does not work. The implementation will break down and the group will find itself sooner or later, back where it began. (Kaner et al. 1996, pp. 140-141)

In the refugeeservicearena, problems are certainly not "routine," rather they are difficult and complex. In responding to the demands of organizational partnerships, the case of the Multicultural Liaison Programme in Ottawa will be discussed.

The Case of the Multicultural Liaison Programme, Ottawa1: The Context for the Programme

Born out of the desire to serve the needs of refugee and immigrant children, the programme fulfills a critical role in the integration of immigrants and refugees into Canadian society by partnering education and settlement services. Over the past seven years, it has evolved into an efficient model for service delivery to immigrant families. In doing so, the Board of Education recognized the value of an NGO, the Ottawa-Carleton Immigrant Services Organization $\left(\mathrm{OCISO}^{2}\right)$ dedicated to immigrant services, as a full and equal partner. Prior to this, the NGO's credibility had to be established. This required what I call, "organizational cultural mediation."

The programme is a "service partnership" between the public French and English boards of education and OCISO. It has grown from an initial team of four workers to the actual team of sixteen Multicultural Liaison Officers (MLOs).

Ensuring that the needs of refugee and immigrant children were met in a timely manner, with minimal administrative procedures and a high degree of quality and consistency was an initial point of agreement for both the school board and OCISO. Since there was a willingness to negotiate the kinds of service that would be offered and the funding for the programme was adequate, the partners assumed it was just a matter of programme planning and delivery.

Setting aside the services delivered to refugee children through this initiative, I would like to present the process required for the partners to be able to work together. For the Multicultural Liaison Programme, the front-line workers became the pioneers who discovered, by trial and error, where there was need for interpretation or mediation between the two organizations. The MLOs became multicultural liaison officers not only between clients and service providers but also between the two institutions involved. Perhaps this role of the MLOs would be that of an "informal mediator" who is described as an insider. With a stake in the outcome, the MLO may not be acceptable to all parties, yet is able to act impartially but may not be seen as impartial, whose role is flexible and multi-sided, and whose authority and values come from her or his position in the group (Beer and Stief 1997, p. 136).

A combination of the very same mediation and negotiation processes that worked for problem solving with the clients, was used to help the service providers to understand each other and to provide consistent support for a team of workers. For example, the lines of responsibility seemed to cross- since an MLO might work based in one or two schools, where of course, the principals are responsible for anything that happens at the site. The MLO, who is an employee of the settlementagency must report to the programme manager at OCISO who is at a different work location and who has absolutely no jurisdiction over activities that occur in the school setting. In addition to that, the MLOs need free access to each other. The combined wisdom of the group is crucial to provide culturally and linguistically appropriate services to the students and their families. 


\section{The Negotiated Solutions}

The schoolboard and OCISO agreed that the MLO would report to the Director of Cross-Cultural Programmes at OCISO, with daily direction to be taken from the principals of the assigned schools. This was the easier part. It is spelled out in the job description for the position and it only requires occasional clarification. The second part of the agreement, accepting that the MLOs are school-based but not school-bound, took a lot more discussion and experimentation. Principals, on the one hand, were told that an MLO would be assigned half-time to their school therefore they assumed "... half-time equals 17.5 hours at my school on a regular schedule." ${ }^{3}$ On the other hand, the management team at OCISO assumed "... All MLOs will come to the agency half-day perweek for team meetings or general staff meetings and they will contribute like any other member of OCISO's staff." ${ }^{4}$ In addition, the MLOs themselves felt that if they needed one of their colleagues to help with specific cases, they should be free to move from one site to the other without having to ask for permission from either the principal or the programme manager. After seven years, there is an implicit agreement thatMLOs are the bestjudges of the urgency or importance of their presence at one or another location as well as the need to maintain a regular schedule at their assigned school bases. They are truly school-based but not schoolbound. Now, both the school board and OCISO understand abit more of the opportunities and constraints in their respective organizations.

As an example of the need for organizational cultural mediation, the interpretation of the guiding principle posed challenges. There was agreement as to what that principle should be for both OCISO and the schoolboard: "Ensuring that the needs of refugee and immigrant children were met in a timely manner, with minimal administrative procedures and a high degree of quality and consistency." 5 However, the guiding principle generated contention because it meant different things to each of the organizations. There were heated discussions centred on the deep meaning of words such as "quality" and we discovered that indeed, almost every word we used, meant different things to each organization. On top of that, "different" frequently meant "my way is right and yours is not." Nonetheless, we struggled with difficult questions such as:

What behaviour is ethical? How employees should behave/be treated? How decisions should be made? Who deserves respect? How organizations should run? Of course, these differences in matters of principle can also be major factors in the dispute. Learning to notice these underlying beliefs can help you to articulate and translate the parties' divergent perspectives. (Beer and Stief 1997, p. 78)

Furthermore, among the challenges in the programme design and decisionmaking processes were assumptions about policies, methodology and procedures. On the one hand, one of those assumptions was that larger "mainstream" organizations are more "professional" than smaller NGOs. On the other, it was assumed that "mainstream" organizations are not really capable of acting in a manner that takes into consideration the individual needs of the refugees.

The need for "organizational cultural mediation" became necessary as we gave shape to the programme. Although it was a muddled process, as cultural mediation sometimes is, we struggled at the institutional level in a manner quite similar to that of the MLOs between clients and service providers. Ioffer Deborah Tannen's explanation: "Because words matter. When we think that we are using language, language is using us. The terms in which we talk about something shape the way we think about it and even what we see"(Tannen 1995, p. 14).

Organizationally, we were using terms based on the perspective of the organization we represented. Tannen proposes that language "invisibly moulds our way of thinking about people, actions and the world around us. This perspective then limits our imagi- nations when we consider what we can do about situations we would like to understand or change" (Tannen 1995, p. 14). In the process of development of the partnership, it was required, so to speak, that we learn to walk in our partner's shoes.

In the course of planning and trying out small scale activities such as interpretation during parent-teacher interviews or informal conversations to present information to staff members or parents, the MLOs often came to a point that we called the "I never thought about it like that!" moment. When this type of comment was made by a parent, a child or a staff member, it usually marked a key moment in terms of trust and understanding. When exactly the samekind of comment was offered at the management level, it became a milestone on the road to partnership.

Occasionally after an intense exchange there is a moment we call the 'Turning Point'. Someone makes an apology, someone offers a concession or a kind word. Then, like water rushing through a breach in the dam, comes an outpouring of personal sharing, of ideas and offers. This dramatic shift from accusations and defensiveness to empathy and resolution is what mediation at its best is all about. It is not something that you as a mediator can make happen, but you can watch for it, make room for it, them move gently on to discussing the mundane details of the agreement. (Beer and Stief 1997, p. 41)

Within the Multicultural Liaison Programme, the organizations' struggle to understand one another's perspective through the work of the MLOs created a shared framework of understanding. This framework, in turn, allowed constructive solutions reflecting the values of both OCISO and the school board. Indeed the programme success is largely due to the partner's ability to constantly adapt the services for the clients, while maintaining consistency in the goals that both organizations hope to attain. 


\section{The Agreements and Understandings Sustaining the Partnership}

The written guidelines, partnership agreements, and "legal" documentation for the Multicultural Liaison Project are minimal. Yet, this might be the most interesting part of the whole partnership (Our "handshake" was enough to get it going!). There is, however, an extensive series of shared assumptions that now form the basis for our agreements and understandings. This framework of understanding that is present when the programme is running at its best integrates key elements that help to establish the "rules of the game."

These shared perspectives developed gradually and we estimate that it took at least three years of work for the partnership to reach this point. The MLOs, through constant feedback to both the school principals and the OCISO programmemanager, provided the means for the partners to learn to "walk in each other's shoes." The key areas where "shared perspectives" have been of tremendous help are listed below with a few samples of "things we understand the same way" to illustrate the point.

Challenges in the Work Environment One of the ongoing discussions in the partnership is the need to strike a balance between flexibility to meet the needs of the clients (and by clients I mean students, their families, school staff and service providers who refer refugees and immigrants to the programme) and a degree of consistency in the services offered so that these same clients do not have to "guess" what the MLOprogramme will offer. During the initial stages there was great interest in having the same programme at all locations. The field work of the MLOs very quickly highlighted the opportunities that would be missed if the programme was inflexible in its approaches or if the supervisors insisted on "traditional" nine to five schedules for the workers. Those discussions generated the following understandings.

\section{A Sample of Shared Understandings}

Among these set of understandings, runs a common thread of flexibility and adaptability for all parties involved.

* The members of the MLOteam work at one or two school sites and report to the programmemanager atOCISO who is at a different work location.

* School principals who are responsible for anything that happens in a school site are extremely busy and not always available for consultation.

* Client's needs vary a great deal.

* MLOsneed free access to each other.

* The combined wisdom of the group is crucial to the success of the programme.

* Access to community resources varies depending on the neighbourhood. Some have services that are nearby and accessible; other neighbourhoods have very few resources.

* The school's priorities for client services vary from one site to the other.

* The MLOs work in elementary and high schools. The activities that might suit the pace and style of each environment are usually quite different.

Thus, the result of our shared understanding is that the MLOs have the flexibility required to perform their job effectively. Their duties or assignment to strictly one school are not rigidly defined.

\section{Priorities}

A second area where constant negotiation takes place is the ranking of priorities for service. Maybe the only assumption that we all shared from the beginning was that the MLOs could not do everything, for everybody, all the time. Again, the MLOs havebeen instrumental in pinpointing the areas where there must be a "shared understanding" for them to be able to function and make decisions in a consistent manner. I would stress that for the partnership what is important is that there is agreement. The actual content is more of an operational matter. Let us visit some of the agreements reached.

* There is agreement between the principal, the programme manager and the MLO about the settlement service priorities for the year and how the MLO will proceed to meet them.

* There is an agreement between the principal, the programme manager and the MLO about the role of the MLO and how he or she will contribute to the school's priorities for the year.

* The staff at the school have a clear sense of the MLO's functions. (Again, the fact that "there is a clear sense" is the crucial part. The MLO functions may vary at each school).

* The MLO team has a clear sense of the programme boundaries for service delivery.

* There is an agreement between the programme manager and the MLOs about the service priorities for the year and how the team will meet them.

* There is an agreement between the executivedirector, the programmemanager and the MLOs about the agency's service priorities for the year and how theMLOs will contribute to meet them.

\section{Communications}

One of thestrengths of the programme is the diversity of cultural and linguistic backgrounds within the team. It is also one of the potential areas of confusion when a specific set of skills is required. The crucial agreement is that the MLO is the "key" to access a team of multidisciplinary, multicultural workers. In this area, the "shared understandings" focus more on establishing credibility for the MLO as an expert in community liaison and intercultural communication.

* The MLO at the school is the channel used to access the services of other MLOs.

* There is an efficient protocol for accessing the services of other MLOs.

* The MLO has been accepted as a member of the school staff and participates (whenever possible) in staff meetings, school activities, etc.

* The MLO is used as a resource for intercultural communication, and not simply a problem solver for one or two cultural groups.

* The MLOis deemed knowledgeable about resources available in the community. 
* There is an agreement between the MLOs, the programmemanagerand the school principals on when to consult and when to make independent decisions.

This framework of understandings and agreements was essential to the success of the MLOProgramme. Nonetheless, there were other elements that we recognized were necessary to sustain the partnership: financial resources time and a team approach.

\section{Nurturing the Partnership}

In addition to "shared understandings", there are other important elements that had great impact on the success of the Multicultural Liaison Programme. Abrief discussion on each one follows.

\section{Financial Resources}

The collaboration of several funding partners with complementary mandates was essential in order to establish a programme that addressed the multiple needs of immigrant and refugee families, school staff, students and the community at large. A programme with a narrow focus does not work very well in a schoolsetting where one is expected to pitch in and help everyone and not a select group of clients only.

\section{Time}

Most of the implicit agreements, which govern the lines of communication and responsibility for the partners and staff involved in the Multicultural Liaison Programme, were developed by trial and error method over the length of the partnership. It took time to learn about each other's strengths and weaknesses. It took time and hard work to earn the trust of the parents, the students and the school staff since relationships of trust are based on repeated positive interaction. By keeping promises, maintaining an objective and neutral position and helping parents, students and staff to manage the small matters of day-to-day situations, theMLOs built trust with the three client groups. It also took time to develop effective links with other service providers in the community and with the school resource staff who are not there on a daily basis. More than anything else, it took time to build a team of multicultural, multidisciplinary liaison experts.

\section{Multiplying Talent: A Team Approach}

The MLOs depend to a great extent on other MLOs for interpretation, facilitation and consultation. Their job shares elements of the settlement, outreach, community development, and crisis worker. This multifaceted role makes it difficult to explain to an "outsider" why the usual strategies might backfire when applied in a school setting.

What was clear to us is that the combined wisdom of the group is crucial to the success of the programme. At their weekly team meetings, the MLOs present situations that are specially challenging or strategies that have worked exceptionally well. They consult with their colleagues since another MLO will understand the context of the intervention or someone in the team might havealready encountered a similar situation. In addition, MLO is the link to a collective pool of languages and intimate knowledge of cultural contexts that would be almost impossible to find in a single person. Thus, if translation or cultural interpretation is needed, all they have to do is call another member of the team who requires only minimal briefing to facilitate an intervention.

\section{Results}

The time and resource investment during the planning and early implementation stages of the Multicultural Liaison Programme at a new school has consistently resulted into more effective service delivery with clear lines of communication and responsibility. This translates into direct benefits for immigrant and refugee children and their families because the settlement and integration services are provided in a proactive and minimally intrusive manner that networks the resources of two sectors with complementary mandates.

Having said that, I offer a word of caution. After seven years of successful partnership, it is sometimes difficult to establish realistic expectations for the first year of the programme in a new school location. After all, it would seem logical that if there is a programme with good guidelines, tested strategies and a consistent approach, then implementation would be a matter of putting the plan into action and the new site would be "up to speed" in no time at all. Unfortunately, this does not happen quite so fast.

Building a successful relationship takes commitment, resources, time and skilled facilitators. Each potential partner has specific needs which are disclosed over a period of time. It is quite helpful to listen to others who have travelled down that path before, but each partnership as new relationship is uniquely shaped by the people who are involved in it in a particular context.

The Multicultural Liaison Programme is no exception to this rule and it shows once again why the developmental stages of a service partnership should be considered as two different projects with overlapping goals. In this case, the "service project" aims to facilitate the settlement and integration of new Canadians. By the end of the first year, given optimal conditions, one would expect the following indicators of involvement from refugee families:

*Increased interaction and collaboration between staff and parents;

${ }^{*}$ Increased participation of parents in school activities;

*Increased participation of students in non-mandatory school activities; and

*Increased consultation with the MLOinitiated by parents or school staff.

The "partnership project", equally important, concentrates in creating a sustainable arrangement for collaboration among the service providers. By the end of the first year, given optimal conditions, the pattern for the programme activities in the school would be established and there would be a clear understanding of the links of communication and responsibilities among all parties involved. At this point, the MLO is used as a "broker" to facilitate communication and access by students, parents and school staff.

\section{Conclusion}

The developmental stages of a service partnership should be considered as 
two different projects with overlapping goals. One of the projects would focus on the services delivered to refugees and immigrants. The other project, equally important, would concentrate in creating a partnership among the service providers. A shared framework of understanding and agreements is required to create a sustainable partnership for collaboration among service providers.

The case of the Multicultural Liaison Programme demonstrates that for effective collaboration between service providers it is as important to build the "context" of service (shared understanding, trusting the professional ability of colleagues, strengthening the network of service providers) as it is to deliver direct service to students and their families. The time and resource investment during the planning and early implementation stages of the Multicultural Liaison Programme has consistently resulted in effective service delivery, clear lines of communication and responsibility and a proactive, minimally intrusive pattern of intervention. The Multicultural Liaison Programme illustrates the importance of the initial investment required for "Service Interpretation" among institutions that are truly interested in the development of service partnerships.

\section{References}

Tannen, Deborah. 1995. The Argument Culture. Random House.

Beer, Jennifer E. and Eileen Stief. 1997. The Mediator's Handbook. New Society Publishers.

Pinto, Miranda. 1998. (Spring/Summer). "Building Equitable Partnerships." OCASI Newsletter, pp. 6-7.

Di Zio, Josie. 1998. (Spring/Summer). "Another Look at Partnership." OCASINewsletter, p. 3.

Kaner, Sam, Jenny Lind, Catherine Toldi, Sarah Fisk and Duane Berger. 1996. Facilitator's Guide to Participatory Decision-Making. New Society Publishers in collaboration with Community at Work.

Epstein, Joyce L., Lucretia Coates, Karen Clark Salinas, Mavis G. Sanders, and Beth S.
Simon. 1997. School, Family and Community Partnerships. Your Handbook for Action. Corwin Press Inc.

Vargas, Claudia María. 1999. "Cultural Interpretation for Refugee Children: The Multicultural Liaison Programme, Ottawa,Canada." Refuge, Vol.18,No.2,pp. 32-41.

\section{Notes}

Views expressed in this article are the author's and should not be construed as the views of CIC or OCASI.

1. For excellent information on the essence of this programme, see Claudia María Vargas, "Cultural Interpretation for Refugee Children: The Multicultural Liaison Programme, Ottawa, Canada," Refuge, Vol. 18, No. 2, (April 1999), pp. 32-41.

2. Ottawa-Carleton Immigrant Services Organization is a non-profit, charitable organization established in 1974. Its services include settlement, counselling, employment, and cross-cultural education.

3. Planning meetings, MLO Programme, 1994.

4. Planning Meetings, MLOProgramme, 1994.

5. Interview with ESL Programme Manager, Ottawa Board of Education, Summer 1992.ם

\title{
Refuge
}

\section{Canada's Periodical on Refugees}

\section{Published six times a year by the Centre for RefugeeStudies, York University, Toronto.}

\author{
Available from: \\ Centre for Refugee Studies, York University \\ Suite 333, York Lanes, 4700 Keele St. \\ Toronto ON M3J $1 \mathrm{P3}$ \\ Fax: (416) 736-5837 - Email: refuge@yorku.ca \\ http://www.yorku.ca/research/crs
}

